\title{
Analysis of citric acid and D-isoascorbic acid in beverages by High performance liquid chromatography
}

\author{
Rui Wang ${ }^{1,2}$, Shiwen $\mathrm{Hu}^{2, *}$, and Jie $\mathrm{Chen}^{2}$ \\ ${ }^{1}$ Chongqing Collaborative Innovation Center for Functional Food, Chongqing University of Education, Chongqing 400067, China \\ ${ }^{2}$ College of Biological and Chemical Engineering, Chongqing University of Education, Chongqing 400067, China
}

\begin{abstract}
In this study, high performance liquid chromatography (HPLC) was used to analysis the content of citric acid and D-isoascorbic acid in beverages. The samples were separated by $\mathrm{C} 18$ chromatography column, $0.1 \%$ phosphoric acid solution was used as the mobile phase with the flow rate of $0.5 \mathrm{~mL} / \mathrm{min}$, the column temperature was $35^{\circ} \mathrm{C}$, and the detection wavelength was $210 \mathrm{~nm}$. The results showed that the content of citric acid and D-isoascorbic acid has a good linear correlation ( $r>0.99)$ within the range of $50 \mu \mathrm{g}$ to 200 $\mu \mathrm{g}$. The selectivity, recovery and precision of citric acid and D-isoascorbic acid were suitable. Meanwhile, this method could be used to detect the content of citric acid and D-isoascorbic acid in beverages.
\end{abstract}

\section{Introduction}

At present, food additives are widely used in the food industry. As we all know, food additives will not cause harm to the human body within the appropriate dosage, but if the dosage exceeds the standard, they may cause various forms of toxicity [1]. It is reported that the long-term lowdose excessive intake of colorant additives may lead to the decline of adult fertility, affect the intellectual development of children, and cause some excessive behaviors in children [2]. Therefore, strict standards have been established for the use of food additives in China [3]. As a kind of fastconsuming food, beverage has a huge market demand. In order to make the taste better and extend its shelf life, many manufacturers usually add some appropriate types of food additives to the beverage [4]. D-isoascorbic acid, also known as isovitamin $\mathrm{C}$, is a common antioxidant and has many application prospects in beverages [5]. Meanwhile, citric acid is often used as a kind of sour agent in beverages. It is not only has the taste of natural fruit, but also has the effect of anti-oxidation. Moreover, it can effectively prevent browning and stickiness on the surface of foods and play a role in color protection. Currently, the detection methods of food additives in beverages mainly include the high performance liquid chromatography [6, 7], gas chromatography [8] and liquid chromatography-mass spectrometry [9], etc. However, citric acid and Disoascorbic acid can only be detected separately by the existing methods, and there is no method for detecting them both at the same time. Therefore, this study aims to establish a high performance liquid chromatography method that can simultaneously detect citric acid and Disoascorbic acid in beverages, and this method could be used to determine the content of related substances in commercially available beverages.

\section{Materials and Methods}

\subsection{Chemicals and reagents}

Standard D-isoascorbic acid and standard citric acid were purchased from Shanghai yuanye Bio-Technology Co., Ltd (Shanghai, China). Ultrapure water used in the experiment was of Milli-Q quality (Millipore Corp., Bedford, MA, USA). HPLC-grade Phosphoric acid was obtained from Chron Chemicals Co., Ltd (Chengdu, China). The twenty-nine kinds of beverage samples used in this experiment were randomly selected in the supermarket.

\subsection{Preparation of solutions}

$10 \mathrm{mg}$ of citric acid and $10 \mathrm{mg}$ of D-isoascorbic acid standards were accurately weighed into a $10 \mathrm{~mL}$ volumetric flask respectively, dissolved with an appropriate amount of ultrapure water, then added the ultrapure water to make the volume to obtain a standard stock solution with a concentration of $1.0 \mathrm{mg} / \mathrm{mL} .1 \mathrm{~mL}$ of the standard stock solutions of citric acid and Disoascorbic acid were drawn into a $10 \mathrm{~mL}$ volumetric flask, ultrapure water was used to make the volume. The solution was filtered with a $0.22 \mu \mathrm{m}$ filter membrane to obtain a mixed standard solution.

\subsection{Sample preparation}

$1 \mathrm{~mL}$ of beverage sample was put into a $10 \mathrm{~mL}$ volumetric flask respectively. An appropriate amount of ultrapure water was mixed with the sample and made to the volume. The solution was filtered with a $0.22 \mu \mathrm{m}$ water-based

\footnotetext{
*Corresponding author: wenfeng970211@sohu.com
} 
filter membrane to obtain the sample solution.

\subsection{Instrumentations and chromatographic conditions}

Thermo Fisher Scientific UltiMate3000 HPLC System (Thermo Fisher Scientific, USA) equipped with DAD detector and an accucore C18 column $(150 \mathrm{~mm} \times 4.6 \mathrm{~mm}$, $2.6 \mu \mathrm{m}$; Thermo Fisher Scientific, USA) was used in this research. The detection wavelength was $210 \mathrm{~nm}$. Meanwhile, $0.1 \%$ phosphoric acid solution was used as the mobile phase with the flow rate of $0.5 \mathrm{~mL} / \mathrm{min}$, the column temperature was $35^{\circ} \mathrm{C}$, and the injection volume was $5 \mu \mathrm{L}$.

\subsection{Method validation}

\subsubsection{Selectivity}

The mixed standard solution of D-isoascorbic acid and citric acid was determined according to the HPLC method. The retention time and the chromatographic peaks of two additives were obtained to study the selectivity of the detection method.

\subsubsection{Linear range}

The appropriate amount of D-isoascorbic acid standard solution and citric acid standard solution was precisely measured and diluted with mobile phase to the concentration of $20,40,60,80,100 \mu \mathrm{g} / \mathrm{mL}$, then analyzed by the established detection method. After that, the concentrations of standard substance were set as abscissa and the peak area were set as ordinate to draw the standard curves.

\subsubsection{Precision}

The appropriate amount of D-isoascorbic acid standard solution and citric acid standard solution was taken. It was detected six times to calculate the intra-day precision. Meanwhile, it was detected once a day to calculate the inter-day precision in a five consecutive day period.

\subsubsection{Recovery}

$50 \mu \mathrm{g} / \mathrm{mL}, 100 \mu \mathrm{g} / \mathrm{mL}$ and $150 \mu \mathrm{g} / \mathrm{mL}$ of D-isoascorbic acid standard solution and citric acid standard solution were added respectively to the $100 \mu \mathrm{g} / \mathrm{mL}$ standard mixed solution, and perform five times detection according to the established HPLC method. Then the recoveries of Disoascorbic acid and citric acid were calculated respectively.

\subsection{Determination of D-isoascorbic acid and citric acid in beverages}

Twenty-nine kinds of beverages were randomly selected from the market. The content of D-isoascorbic acid and citric acid in each beverage was detected by the established detection method.

\section{Results and Discussions}

\subsection{Selectivity}

The retention time of D-isoascorbic acid and citric acid was $2.5 \mathrm{~min}$ and $2.8 \mathrm{~min}$ respectively as shown in Figure 1 , and the separation of the two additives was obvious. These results showed that the selectivity of the HPLC method meets the experimental requirements.

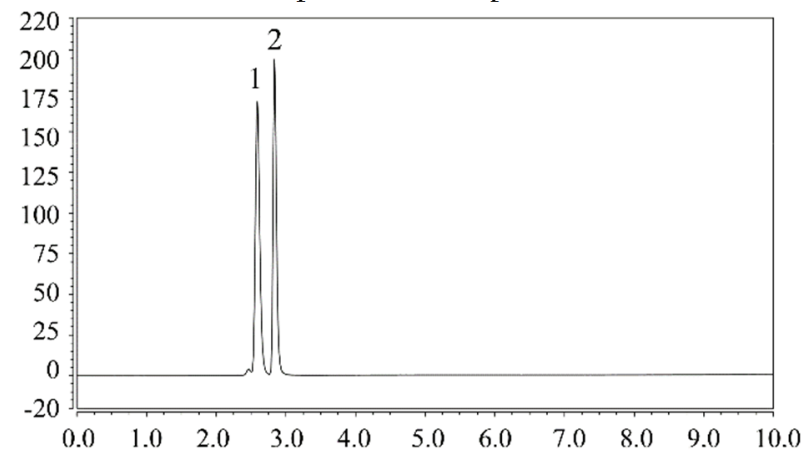

Fig. 1. HPLC chromatogram of standard. (1) D-isoascorbic acid; (2) citric acid.

\subsection{Linear range}

As shown in Table 1, the correlation coefficient (r) of Disoascorbic acid and citric acid was 0.998 and 0.996 respectively. The results demonstrated that the content of D-isoascorbic acid and citric acid has a good linear correlation ( $r>0.99$ ) within the range of $50 \mu \mathrm{g}$ to $200 \mu \mathrm{g}$.

Table 1. Standard curve and linear range of two additives.

\begin{tabular}{|c|c|c|c|}
\hline additive & $\begin{array}{c}\text { standard } \\
\text { curve }\end{array}$ & $\begin{array}{c}\text { correlation } \\
\text { coefficient }(\mathbf{r})\end{array}$ & $\begin{array}{c}\text { linear } \\
\text { range } \\
(\boldsymbol{\mu g} / \mathbf{m L})\end{array}$ \\
\hline $\begin{array}{c}\text { D-isoascorbic } \\
\text { acid }\end{array}$ & $\begin{array}{c}\mathrm{Y}=0.01 \mathrm{X}+ \\
0.0438\end{array}$ & 0.998 & $50-200$ \\
\hline citric acid & $\begin{array}{c}\mathrm{Y}=0.1098 \\
\mathrm{X}+0.602\end{array}$ & 0.996 & $50-200$ \\
\hline
\end{tabular}

\section{3 precision}

As shown in Table 2, the intra-day precision of Disoascorbic acid and citric acid was $0.602 \%$ and $1.366 \%$ respectively. Meanwhile, the inter-day precision of $\mathrm{D}$ isoascorbic acid and citric acid was $0.815 \%$ and $1.601 \%$ respectively. These results indicated that the HPLC method has a good precision.

Table 2. Intra-day and inter-day precision.

\begin{tabular}{|c|c|c|}
\hline \multirow{2}{*}{ additive } & \multicolumn{2}{|c|}{ RSD (\%) } \\
\cline { 2 - 3 } & Intra-day & Inter-day \\
\hline D-isoascorbic acid & 0.602 & 0.815 \\
\hline citric acid & 1.366 & 1.601 \\
\hline
\end{tabular}




\subsection{Recovery}

The recoveries of D-isoascorbic acid were ranged in $86 \%$ to $112 \%$, and the recoveries of citric acid were ranged in $87 \%$ to $97 \%$, respectively (Table 3 ). It can be seen from the results that the recovery of the HPLC method was good.

Table 3. Recoveries of two additives.

\begin{tabular}{|c|c|c|c|c|}
\hline \multirow{2}{*}{$\begin{array}{c}\text { Concentration } \\
\text { of added } \\
\text { standard } \\
(\mu \mathrm{g} / \mathrm{mL})\end{array}$} & \multicolumn{2}{|c|}{$\begin{array}{c}\text { D-isoascorbic } \\
\text { acid }\end{array}$} & \multicolumn{2}{|c|}{ citric acid } \\
\hline & $\begin{array}{c}\text { Recover } \\
\text { y (\%) }\end{array}$ & $\begin{array}{l}\text { RSD } \\
(\%)\end{array}$ & $\begin{array}{c}\text { Recovery } \\
(\%)\end{array}$ & $\begin{array}{l}\text { RSD } \\
\text { (\%) }\end{array}$ \\
\hline 50 & 95 & 0.9 & 87 & 1.3 \\
\hline 100 & 112 & 1.2 & 97 & 1.6 \\
\hline 150 & 86 & 1.6 & 94 & 0.9 \\
\hline
\end{tabular}

\subsection{Determinations of D-isoascorbic acid and citric acid in beverages}

As shown in Table 4, the content of D-isoascorbic acid and citric acid in beverages were analyzed by HPLC. The results of the study showed that citric acid was added to all of the 29 kinds of beverages, while D-ascorbic acid was not added to 8 kinds of beverages. The content of D-isoascorbic acid in 29 kinds of beverages was mostly in the range of 100 to $200 \mu \mathrm{g} / \mathrm{mL}$, and there were 4 samples with added Disoascorbic acid below $100 \mu \mathrm{g} / \mathrm{mL}$, while there were 6 samples with added D-isoascorbic acid above $200 \mu \mathrm{g} / \mathrm{mL}$. Moreover, the content of citric acid was mostly in the range of 10 to $30 \mu \mathrm{g} / \mathrm{mL}, 14$ samples with concentration below $10 \mu \mathrm{g} / \mathrm{mL}$, and 4 samples above $30 \mu \mathrm{g} / \mathrm{mL}$. Therefore, the established high performance liquid chromatography method in this study could detect the content of Disoascorbic acid and citric acid in beverages simultaneously and accurately.

Table 4. Determination of D-isoascorbic acid and citric acid in beverages.

\begin{tabular}{|c|c|c|}
\hline Sample & $\begin{array}{c}\text { D-isoascorbic acid } \\
(\boldsymbol{\mu g} / \mathbf{m L})\end{array}$ & $\begin{array}{c}\text { citric acid } \\
(\boldsymbol{\mu g} / \mathbf{m L})\end{array}$ \\
\hline 1 & 74.02 & 4.32 \\
\hline 2 & 605.02 & 23.62 \\
\hline 3 & not detected & 8.39 \\
\hline 4 & 153.42 & 5.17 \\
\hline 5 & not detected & 12.67 \\
\hline 6 & 253.62 & 7.67 \\
\hline 7 & 206.72 & 14.54 \\
\hline
\end{tabular}

\begin{tabular}{|c|c|c|}
\hline 8 & 40.72 & 4.50 \\
\hline 9 & 47.12 & 2.63 \\
\hline 10 & 138.12 & 10.75 \\
\hline 11 & not detected & 20.40 \\
\hline 12 & 598.62 & 28.12 \\
\hline 13 & 181.82 & 18.42 \\
\hline 14 & 183.92 & 8.55 \\
\hline 15 & not detected & 39.67 \\
\hline 16 & 142.42 & 11.58 \\
\hline 17 & 116.92 & 14.64 \\
\hline 18 & 200.82 & 3.96 \\
\hline 19 & 236.22 & 41.32 \\
\hline 20 & not detected & 11.90 \\
\hline 21 & not detected & 1.84 \\
\hline 22 & 106.42 & 31.70 \\
\hline 23 & 146.42 & 1.13 \\
\hline 24 & not detected & 6.28 \\
\hline 25 & not detected & 1.34 \\
\hline 26 & 136.92 & 4.19 \\
\hline 27 & 51.42 & 13.94 \\
\hline 28 & 190.92 & 69.12 \\
\hline 29 & 120.22 & 4.35 \\
\hline
\end{tabular}

\section{Conclusion}

This study was optimized on the basis of the existing detection methods of $\mathrm{D}$-isoascorbic acid and citric acid to establish a high performance liquid chromatography method that can simultaneously determine the content of D-isoascorbic acid and citric acid in beverages. The samples were separated by $\mathrm{C} 18$ chromatography column, $0.1 \%$ phosphoric acid solution was used as the mobile phase with the flow rate of $0.5 \mathrm{~mL} / \mathrm{min}$, the column 
temperature was $35^{\circ} \mathrm{C}$, and the detection wavelength was $210 \mathrm{~nm}$. The results showed that the retention time of Disoascorbic acid and citric acid was $2.5 \mathrm{~min}$ and $2.8 \mathrm{~min}$ respectively. The content of $\mathrm{D}$-isoascorbic acid and citric acid has a good linear correlation $(r>0.99)$ within the range of $50 \mu \mathrm{g}$ to $200 \mu \mathrm{g}$. Meanwhile, the recoveries of Disoascorbic acid were ranged in $86 \%$ to $112 \%$, and the recoveries of citric acid were ranged in $87 \%$ to $97 \%$, respectively. The precision of citric acid and D-isoascorbic acid were suitable. Furthermore, the content of Disoascorbic acid in 29 kinds of beverages was mostly in the range of 100 to $200 \mu \mathrm{g} / \mathrm{mL}$, while the content of citric acid was mostly in the range of 10 to $30 \mu \mathrm{g} / \mathrm{mL}$. In summary, this established HPLC method could analyze the content of D-isoascorbic acid and citric acid in beverages quickly. Therefore, this HPLC method has certain application value.

\section{Acknowledgments}

This research was funded by Teaching Reform Project of Chongqing University of Education (JG201730).

\section{References}

1. H. F. Liu, X. Zhou. Automotive Quality, 4, 42 (2006)

2. Q. Liu, X. Li, X. X. Wu, L. L. Liu, P. Liu. Physical Testing and Chemical Analysis (Part B: Chemical Analysis), 53, 693 (2017)

3. J. Wei, Z. M. Guo, F. F. Zhang, X. M. Liang. Journal of Food Safety \& Quality, 4, 395 (2013)

4. X. L. Fang. The Food Industry, 39, 314 (2018)

5. Y. T. Dai, J. Q. Yang, S. L. Ge, S. Y. Yu. Food and Fermentation Sciences \& Technology, 55, 81 (2019)

6. M. X. Liu, Q. Zhou, W. P. Chen. Science and Technology of Food Industry, 34, 376 (2013)

7. Y. Zhang, H. M. Wu, W. Wang, J.Q. Wang, L. P. Bai. Journal of Food Safety \& Quality, 27, 18 (2010)

8. Y. Luan, J. Zhao, W.Y. Quan, H. Z. Li. Chinese Journal of Public Health 20, 487 (2004)

9. R.H. Ke, L. J. Wang, H.M. An, J.J. Yin, Q. H. Song. Beverage Industry, 16, 35 (2013) 